\title{
Determinants of technical efficiency among dairy farms in Wisconsin
}

\author{
V. E. Cabrera, ${ }^{* 1}$ D. Solís, $\ddagger$ and J. del Corral§ \\ *Department of Dairy Science, University of Wisconsin, Madison 53706 \\ †Division of Marine Affairs and Policy, University of Miami, Miami, FL 33149 \\ ‡Division of Agribusiness, Florida A\&M University, Tallahassee 32307 \\ $\S$ Department of Economic and Financial Analysis, University of Castilla-La Mancha, Ciudad Real 13071, Spain
}

\begin{abstract}
The US dairy sector is facing structural changes including a geographical shift in dairy production and a tendency toward the implementation of more intensive production systems. These changes might significantly affect farm efficiency, profitability, and the long-term economic sustainability of the dairy sector, especially in more traditional dairy production areas. Consequently, the goal of this study was to examine the effect of practices commonly used by dairy farmers and the effect of intensification on the performance of the farms. We used a sample of 273 Wisconsin dairy farms to estimate a stochastic production frontier simultaneously with a technical inefficiency model. The empirical analysis showed that at a commercial level the administration of bovine somatotropin hormone to lactating cows increased milk production. In addition, we found that production exhibits constant returns to scale and that farm efficiency is positively related to farm intensification, the level of contribution of family labor in the farm activities, the use of a total mixed ration feeding system, and milking frequency.
\end{abstract}

Key words: technical inefficiency, stochastic production frontier, intensification

\section{INTRODUCTION}

The US dairy sector is facing dramatic structural changes including a geographical shift in dairy production and a tendency toward the implementation of more intensive production systems. During the last decade, the more traditional dairy states have significantly decreased their number of dairy farms, and the western and southwestern states have rapidly increased their share in the dairy market (Barham et al., 2005; USDA, 2007; Cabrera et al., 2008). Under these circumstances, researchers have suggested that improvement in efficiency is one of the key factors for the survival of

Received April 17, 2009.

Accepted October 5, 2009.

${ }^{1}$ Corresponding author: vcabrera@wisc.edu dairy farms in traditional production areas (Tauer and Belbase, 1987; Tauer, 2001; Alvarez et al., 2008).

Studying farm efficiency and the potential sources of inefficiency are therefore important from a practical and a policy point of view. On the one hand, farmers could use this information to improve their performance. On the other hand, policymakers could use this knowledge to identify and target public interventions to improve farm productivity and farm income (Solís et al., 2009).

Previous literature on this topic has focused on estimating the level of technical efficiency (TE) among samples of dairy farms. To do so, these studies have used either a nonparametric method such as data envelopment analysis (e.g., Tauer, 1998; Jaforullah and Whiteman, 1999; Stokes et al., 2007) or an econometric approach such as stochastic (production, cost, or profit) frontier models (e.g., Heshmati and Kumbhakar, 1994; Cuesta, 2000, Alvarez et al., 2005; Bravo-Ureta et al., 2008). These 2 methodologies have also been used to analyze the potential sources of inefficiencies (e.g., Lawson et al., 2004; Tauer and Mishra, 2006; Murova and Chidmi, 2009). However, Kumbhakar and Lovell (2000) argue that a stochastic frontier model seems to be the most appropriate approach in studies related to the agricultural sector because of its ability to deal with stochastic noise, accommodate traditional hypothesis testing, and allow for single-step estimation of the inefficiency effects.

Consequently, the present study implements a stochastic frontier model to evaluate the determinants of technical efficiency among dairy farms in the State of Wisconsin. This research adds to the literature by examining issues normally neglected in past studies; namely, the effect of practices commonly used by dairy farmers in the United States and the effect of intensification on the performance of the farms. To reach our goal we implemented a version of the traditional stochastic production frontier (SPF) framework that allows for a unified analysis of inefficiency effects. The empirical sample included detailed financial and production information for 273 Wisconsin dairy farms during the 2007 agricultural year. The main results provide estimates of the relative importance of inputs in dairy produc- 
tion and the effects of key factors on the efficiency of the farms. Specifically, we found that the studied dairy farms exhibit constant returns to scale and that farm efficiency is positively linked with farm intensification, the level of contribution of family labor in the farm activities, the use of TMR feeding system, and milking frequency. In addition, the commercial dairy farms included in the analysis show that the administration of the hormone bST to lactating cows positively affects production.

\section{MATERIALS AND METHODS}

\section{Stochastic Production Frontier and Inefficiency Analysis}

To study the determinants of TE we used the SPF methodology developed by Aigner et al. (1977). The SPF method is based on an econometric (i.e., parametric) specification of a production frontier. Using a generalized production function and cross-sectional data, this method can be depicted as follows:

$$
y_{i}=f\left(\mathbf{x}_{i j} ; \boldsymbol{\beta}\right) \cdot \exp \left(\varepsilon_{i}\right)
$$

where $y$ represents output, $\mathbf{x}$ is a vector of inputs, $\boldsymbol{\beta}$ is a vector of unknown parameters, and $\varepsilon$ is the error term. The subscripts $i$ and $j$ denote the farm and inputs, respectively.

In this specific formulation, the error term is farmspecific and is composed of 2 independent components, $\varepsilon_{i}=v_{i}-u_{i}$. The first element, $v_{i}$, is a random variable reflecting noise and other stochastic shocks entering into the definition of the frontier, such as weather, luck, strikes, and so on. This term is assumed to be an independent and identically distributed normal random variable with 0 mean and constant variance iid $\left[N \sim\left(0, \sigma_{v}^{2}\right)\right]$. The second component, $u_{i}$, captures technical inefficiency (TI) relative to the stochastic frontier. The inefficiency term $u_{i}$ is nonnegative and it is assumed to follow a half-normal distribution (Kumbhakar and Lovell, 2000).

An index for TE can be defined as the ratio of the observed output $(y)$ and maximum feasible output $\left(y^{*}\right)$ :

$$
\begin{aligned}
\mathrm{TE}_{\mathrm{i}} & =\frac{y_{i}}{y_{i}{ }^{*}}=\frac{f\left(\mathbf{x}_{i j} ; \boldsymbol{\beta}\right) \cdot \exp \left(v_{i}-u_{i}\right)}{f\left(\mathbf{x}_{i j} ; \boldsymbol{\beta}\right) \cdot \exp \left(v_{i}\right)}=\exp \left(-u_{i}\right) ; \\
\mathrm{TI}_{i} & =1-\mathrm{TE}_{i} .
\end{aligned}
$$

Because $y$ is always $\leq y^{*}$, the TE index is bounded between 0 and 1; TE achieves its upper bound when a dairy farm is producing the maximum output feasible level (i.e., $y=y^{*}$ ), given the input quantities. Jondrow et al. (1982) demonstrated that farm-level TE can be calculated from the error term $\varepsilon_{i}$ as the expected value of $-u_{i}$ conditional on $\varepsilon_{i}$, which is given by

$$
\mathrm{E}\left[u_{i} \mid \varepsilon_{i}\right]=\frac{\sigma_{u} \sigma_{v}}{\sigma}\left[\frac{f\left(\varepsilon_{i} \lambda / \sigma\right)}{1-F\left(\varepsilon_{i} \lambda / \sigma\right)}-\frac{\varepsilon_{i} \lambda}{\sigma}\right],
$$

where $\sigma^{2}=\sigma_{u}^{2}+\sigma_{v}^{2}, \quad \lambda=\sigma_{u} / \sigma_{v}, \quad f(\cdot)$ represent the standard normal density and $F(\cdot)$ the standard normal cumulative density functions. The maximum likelihood estimation of Eq. [1] provides estimators for the variance parameters $\sigma_{u}^{2}$ and $\sigma_{v}^{2}$. Thus, the TE measure for each farm is equal to

$$
\mathrm{TE}_{i}=\exp \left(-\mathrm{E}\left[u_{i} \mid \varepsilon_{i}\right]\right) .
$$

Caudill et al. (1995) extended this framework to analyze the extent to which certain variables influence the inefficiency term $u_{i}$. Specifically, these authors developed a model in which the determinants of inefficiency are evaluated using a multiplicative heteroscedasticity framework. That is,

$$
\sigma_{u i}=\sigma_{u} \exp \left(\mathbf{Z}_{m i} ; \alpha\right)
$$

where $\mathbf{Z}_{m i}$ is a vector of farm-management strategies that explain inefficiency and $\alpha$ are unknown parameters. Given that the inefficiency is assumed to follow a half-normal distribution, a decrease in the variance will lead to increments in the efficiency level. In this approach, the parameters for the production frontier and for the inefficiency model are estimated jointly using the maximum likelihood technique (Caudill et al., 1995).

\section{Empirical Model}

The empirical analysis is based on the estimation of a Cobb-Douglas production function in which both the output and inputs are expressed in logarithmic form. Hence, the estimated coefficients reflect the output elasticities (Kumbhakar and Lovell, 2000). It is important to indicate that preliminary comparisons led to the rejection of the translog functional form.

In this model, the dependent variable is the total milk production sold $(\mathrm{kg})$. Based on the literature and the data available, our empirical model included the following 6 inputs: cow, defined as the number of adult 
Table 1. Descriptive statistics for Wisconsin dairy farms $(n=273,2007$ agricultural year $)$

\begin{tabular}{|c|c|c|c|c|}
\hline Variable (unit) & Mean & $\mathrm{CV}$ & Minimum & Maximum \\
\hline Milk (kg) & $1,335,408$ & 1.31 & 171,172 & $12,185,328$ \\
\hline Cow $(n)$ & 133 & 1.16 & 23 & 998 \\
\hline Feed $(\$)$ & 122,917 & 1.53 & 2,650 & $1,249,075$ \\
\hline Capital (\$) & 90,848 & 0.90 & 11,833 & 541,322 \\
\hline Crop $(\$)$ & 159,759 & 1.02 & 4,977 & $1,115,004$ \\
\hline Labor $(\$)$ & 74,315 & 1.35 & 3,377 & 649,892 \\
\hline Livestock (\$) & 56,314 & 1.95 & 559 & 788,063 \\
\hline bST (\%) & 14 & 1.82 & 0 & 100 \\
\hline TMR (dummy) ${ }^{1}$ & 0.53 & 0.95 & 0 & 1 \\
\hline Pasture (dummy) ${ }^{2}$ & 0.24 & 1.77 & 0 & 1 \\
\hline \multicolumn{5}{|l|}{ Milking system (dummy) ${ }^{3}$} \\
\hline Pipeline & 0.67 & 0.70 & 0 & 1 \\
\hline Flat barn & 0.08 & 3.47 & 0 & 1 \\
\hline Pit parlor & 0.25 & 1.74 & 0 & 1 \\
\hline Milking frequency (dummy) & 0.92 & 0.30 & 0 & 1 \\
\hline Family labor (\%) & 37 & 1.01 & 0 & 100 \\
\hline Housing (dummy) ${ }^{5}$ & 0.38 & 1.28 & 0 & 1 \\
\hline Feed/cow (ratio) & 777 & 0.46 & 96 & 2,027 \\
\hline
\end{tabular}

cows in the herd; feed, defined as the total cost of purchased feedstuffs (US \$); capital, defined as $5 \%$ of the value of land used plus building depreciation to $15 \mathrm{yr}$ of useful life; crop, defined as the total expenses related to crop production measured (US \$; i.e., chemicals, fertilizers, lime, seeds and plant purchases, machinery depreciation, machinery hire expenses, machinery repair, fuel and oil expenses); labor, defined as the total labor including family and hired labor measured (US \$); and, livestock, which includes breeding expenses, veterinary and medicines and other livestock expenses (US \$). In addition, to account for differences in production based on the use of growth hormones we included the control variable $b S T$, which is defined as the percentage of the cows under bST treatment.

As indicated, SPF also allows for a unified analysis of inefficiency effects. The variables included in the inefficiency model were milking system, a set of dummy variables representing each alternative system; namely, flat barn, pit parlor and pipeline (pipeline was the omitted variable); housing, a dummy variable equals 1 for farms that use freestall housing; milking frequency, a dummy variable equals 1 for the farms with a milking frequency equal to 2; and, family labor, the ratio of family labor to total labor measured (US \$). Finally, to study the effect of intensification on efficiency, we included 3 additional variables: feed/cow, defined as the ratio of purchased feedstuffs to the number of cows (a similar approach can be found in Alvarez et al., 2008 and Kompas and Chu, 2006); TMR, a dummy variable equal to 1 for the farm that uses the TMR feeding sys- tem; and pasture, a dummy variable equal to 1 for farms that use pasture feeding systems. This last variable was included to measure the effect of extensive production on TE. Table 1 presents descriptive statistics for all the variables included in the analysis.

\section{Data}

The data used in this study consisted of detailed farm-level information for dairy farms participating in the Agriculture Financial Advisor (AgFA) program managed by the Center for Dairy Profitability at the University of Wisconsin-Madison. The aim of the AgFA program is to collect, analyze and store high quality financial and production information for dairy farms in the State of Wisconsin. More information on the AgFA program can be found at http://cdp.wisc.edu/AgFA. htm.

The empirical sample included 273 dairy farms, and the collected information corresponded to the 2007 agricultural year. The dairy farms in the sample were highly specialized with most of their output coming from dairy sales. All farms were located in Wisconsin, which has traditionally been one of the top states in terms of milk production and dairy farming in the United States.

\section{RESULTS AND DISCUSSION}

Table 2 presents the maximum likelihood parameter estimates for the estimated production frontier model. 
Table 2. Production frontier estimates $(\mathrm{n}=273,2007$ agricultural year)

\begin{tabular}{|c|c|c|}
\hline Variable $^{1}$ & Coefficient & $\mathrm{SD}$ \\
\hline \multicolumn{3}{|l|}{ Frontier } \\
\hline Constant & $7.829^{* * *}$ & 0.225 \\
\hline Cow (n) & $0.779^{* * *}$ & 0.036 \\
\hline Feed $(\$)$ & $0.059^{* * *}$ & 0.020 \\
\hline Capital (\$) & -0.007 & 0.018 \\
\hline Crop $(\$)$ & $0.082^{* * *}$ & 0.019 \\
\hline Labor $(\$)$ & $0.024^{* *}$ & 0.011 \\
\hline Livestock (\$) & $0.062^{* * *}$ & 0.013 \\
\hline bST (\%) & $0.001^{* * *}$ & 0.000 \\
\hline \multicolumn{3}{|l|}{ Inefficiency model } \\
\hline TMR (dummy) ${ }^{2}$ & $-0.513^{*}$ & 0.275 \\
\hline Pasture (dummy) ${ }^{3}$ & 0.393 & 0.246 \\
\hline \multicolumn{3}{|l|}{ Milking system (dummy) } \\
\hline Flat barn & 0.293 & 0.553 \\
\hline Pit parlor & 0.528 & 0.404 \\
\hline Milking frequency (dummy) ${ }^{5}$ & $0.928^{*}$ & 0.564 \\
\hline Family labor $(\%)$ & $-0.008^{* *}$ & 0.003 \\
\hline Feed/cow (ratio) & $-0.002^{* * *}$ & 0.000 \\
\hline Housing (dummy) ${ }^{6}$ & 0.172 & 0.386 \\
\hline Constant & $-3.113^{* * *}$ & 0.708 \\
\hline$\lambda=\sigma_{u} / \sigma_{v}^{7}$ & 1.28 & \\
\hline & 0.09 & \\
\hline Log-likelihood & 191 & \\
\hline
\end{tabular}

${ }^{1}$ Dependent variable is the total milk production sold measured $(\mathrm{kg})$.

${ }^{2}$ Use of $\mathrm{TMR}=1$.

${ }^{3}$ Use of pasture $=1$.

${ }^{4}$ Pipeline is the omitted variable.

${ }^{5}$ Two times daily milking frequency $=1$.

${ }^{6}$ Freestall housing $=1$.

${ }^{7} \lambda=$ weight of variation in technical inefficiency over the variation in the stochastic variable; $\sigma=$ variation in stochastic component of the error variable.

${ }^{*} P<0.10 ;{ }^{* *} P<0.05 ;{ }^{* * *} P<0.01$.

Because all input variables are measured in logarithmic form, the estimated coefficient values represent the partial output elasticities. Following Caudill et al. (1995), we tested the estimated heteroscedastic model against the traditional homoscedastic specification using a likelihood ratio test. The results of this test suggested that the homoscedastic model should be rejected in favor of the heteroscedastic framework implemented in this study.

All output elasticities were positive and statistically significant with the exception of capital. Of all input variables, cow had the highest effect on productivity level with an elasticity equal to 0.78 . That is, a $1 \%$ increase in the number of cows in the herd results in an estimated increase in milk production sold of $0.78 \%$. The next highest elasticity was for crop (0.08), followed by livestock (0.06), feed (0.06), and labor (0.02). In addition, the control variable $b S T$ was positive and statistically significant. This result confirms previous research on the positive effect of bST on milk production (e.g., Bauman et al., 1999) and suggests that commercial farms could consider the use of bST as a mean to improve production.
The scale elasticity (i.e., the sum of all output elasticities) was 1.001, revealing the presence of constant returns to scale (CRS). To corroborate this result we used a likelihood ratio test, which confirmed the presence of CRS. In general terms, CRS suggests that, for the sample of studied dairy farms, there is no proportional relationship between the size of the farms and the level of output produced. Kompas and Chu (2006) further explained that CRS implies that the level of productivity depends on improvements in technology and efficiency, and not necessarily on the scale of the farm.

Table 3 shows that the mean TE in the sample was 0.88 (i.e., $88 \%$ ) with a standard deviation of 0.08 . That is, an average farm in the sample could, in principle, increase its level of milk production sold by $12 \%$ using the current input quantities. Table 3 also presents the distribution of TE scores. This table shows that approximately $83 \%$ of the farmers achieved TE levels of $80 \%$ or higher. It is worth noting that the average level of efficiency obtained here is comparable to the averages presented by Bravo-Ureta et al. (2007) in their meta-regression analysis of TE in agriculture. Those authors reported an $84 \%$ average TE for stochastic frontier studies focusing on dairy farms in developed countries.

The results of the TI model are presented at the end of Table 2. Because of the inverse relationship between TI and TE (see Eq. [2]), the interpretation of the estimated parameters is performed with respect to their effect on TE. That is, a negative effect on TI has a positive effect on TE. This approach is common practice in the literature and facilitates the comparison of our results with previous studies

An important goal of this study was to evaluate the association between intensification and farm efficiency. The empirical results show that the intensification variable feed/cow, defined as the ratio of feed purchased per cow on the farm, had a negative and statistically significant coefficient, implying that an increase in the intensification of a farm would lead to improvements in the efficiency levels. These results agree with the outcomes presented by Alvarez et al. (2008) and Kompas

Table 3. Distribution of technical efficiency (TE) scores

\begin{tabular}{|c|c|c|}
\hline TE interval (\%) & Farms (n) & $\begin{array}{l}\text { Farms in TE } \\
\text { interval }(\%)\end{array}$ \\
\hline $0-49$ & 0 & 0.0 \\
\hline $50-59$ & 3 & 1.1 \\
\hline $60-69$ & 10 & 3.7 \\
\hline $70-79$ & 34 & 12.4 \\
\hline $80-89$ & 89 & 32.6 \\
\hline $90-100$ & 137 & 50.2 \\
\hline Mean TE & \multicolumn{2}{|c|}{88} \\
\hline SD TE & \multicolumn{2}{|c|}{0.08} \\
\hline
\end{tabular}


and $\mathrm{Chu}$ (2006) for dairy farms in northern Spain and Australia, respectively.

Another common practice implemented by more intensive farms is the use of the TMR. This feeding strategy blends all feedstuffs into a complete ration with the required level of nutrients. Our results show that TMR is positively associated with higher levels of TE. This result could be explained by the fact that cows receiving TMR have limited opportunity to sort out individual ingredients of the diet, which allows greater flexibility to feed the correct amounts for particular stages of lactation and production levels. Thus, the use of TMR would result in a consistency of ingredients that improve fermentation and digestibility by rumen bacteria, which could be translated into better intake and consequently improved milk production (Soriano et al., 2001).

The use of pasture, a practice commonly associated with extensive farming, although not statistically significant, had a negative relationship with TE. Numerous studies have documented that pasture systems result in lower milk yields because of its negative effect on feed efficiency (Kolver and Muller, 1998; Dartt et al., 1999; Bargo et al., 2002).

The empirical results clearly show that a higher proportion of family labor over the total labor leads to increase TE. This result agrees with Carter (1984) who argued that, in agricultural production, family members seek to maximize family welfare rather than individual welfare and consequently, provide a greater effort toward production.

Milking frequency was also found to be significantly associated with TE. Specifically, farms milking their cows more than twice per day $(\mathbf{2} \times)$ were more efficient than those with a milking frequency of just $2 \times$. This result agrees with the literature. Indeed, Erdman and Varner (1994) reported that daily milking frequencies of $3 \times$ and $4 \times$ have, respectively, 3.5 and $4.9 \mathrm{~kg}$ of additional milk produced per day per cow. In addition, Dahl et al. (2004) reported that more frequent milking in early lactation stages has been found to improve milk production efficiency.

The set of dummy variables included to measure the influence of the milking systems on TE was not statistically significant, suggesting that there are no significant differences in TE between the 3 studied parlor technologies (i.e., flat barn, pit parlor, and pipeline). We would expect that pit parlor, a technology associated with modern dairy practices (Wagner et al., 2001; Wronski et al., 2007), would show higher TE over older systems such as pipeline or flat barns.

Furthermore, our analysis showed that the type of housing did not have significant effect on TE. It could be argued that freestall housing, a modern dairy farm- ing strategy, may have a positive effect on efficiency because it facilitates herd management and cow comfort. However, our sample included many small farms using a variety of bedded-pack designs as an alternative to freestalls, indicating that these housing systems could be as efficient as freestalls depending on the detailed management provided.

We conjecture that the nonsignificance found in this study for the parlor system and housing could be explained by the fact that the other management strategies included in the TI model (i.e., farm intensification, milking frequency, and the type of labor) are more important in explaining the overall farm efficiency among the studied farms. However, it is worth noting that the literature on this subject presents mixed results. On the one hand, Wronski et al. (2007), Bewley et al. (2001a), and Wagner et al. (2001) argue that milking systems and housing are positively correlated with the farm efficiency. On the other hand, Tauer (1993) found that stanchion barns were as efficient as milking parlors. Hallan and Machado (1996) argue that there is little evidence that higher levels of facilities, machinery, or equipment (related to milking parlors and freestall housing) are associated with increased efficiency. And Bewley et al. (2001b) reported that differences in dairy housing types were not a major predictor of labor efficiency.

The parlor system and housing would be expected to be positively correlated to the number of cows in the farm (Gribble, 2003; Wronski et al., 2007). To test this hypothesis, we ran an alternative TI model including variable cow. Both alternative specifications displayed similar outcomes (i.e., nonsignificance for housing and milking parlor). Additionally, the variable cow was shown not to be significant in explaining the farm TE. This latter result is important for farms in the Midwest and Northeast regions of the United States and for farms in Canada, in which herd size increase would not always be the answer to reach economic sustainability.

\section{CONCLUSIONS}

This study examined the effect of practices commonly used by dairy farmers in the United States and the effect of intensification on the performance of the farms using an SPF and a sample of 273 Wisconsin dairy farms. Our results offer valuable information on the determinants of TE among farms in traditional dairy areas. However, the future of the dairy industry in more traditional dairy states remains unknown.

The empirical results showed that the variable with the highest effect on production is the number of cows on the farm followed by the total expenditure in crops, feeding, livestock, and labor. Farms on which cows are 
supplemented with bST also show a higher level of production. We found that there was not a proportional relationship between the size of the farms and the level of output produced, which implies that the level of productivity depends on improvements in technology and efficiency, not on the size of the farm.

The average level of TE in the sample was $88 \%$, which suggests that, from a technical standpoint, the opportunity exists to expand milk production using the current level of inputs and the technologies already available in the area. These results suggest that dairy farmers in Wisconsin can improve their productivity and efficiency if they take advantage of more efficient farm practices. We know from our results that using $\mathrm{bST}$, more intensive production systems or $>2 \times$ milking improve production and TE. However, we do not know if these strategies might attain higher economic efficiency. The study of economic efficiency merits careful consideration and could be an area for future refinement of the study implemented here.

On the other hand, our results offer some insights in understanding the potential future of this sector in more traditional dairy states. Ball (2009) showed that during the last decade, traditional dairy states in the United States have decreased their level of productivity, while states in the American West and Southwest have displayed significant improvements. Even though improving the TE of milk production in Wisconsin is possible, it is questionable whether this level of improvement would make Wisconsin dairy producers as efficient or competitive as producers in other US regions. To answer this question, a study of larger scope will be needed using detailed farm-level information for representative farms in different geographical locations.

Last, although some of the variables included in the inefficiency model displayed nonsignificant effects in explaining TI, they show some interesting signs and tendencies. Thus, the relationship between TE and milking systems and housing facilities merits further research using a larger sample of farms in alternative environments. In addition, we envision that with increased awareness of the environmental effects of dairy production as well as more stringent environmental regulations, activities such as manure management and other environmental managerial activities will become essential in the day-to-day dairy farm activities. Consequently, studying the effect of environmental management practices on TE could be an area for future refinement of the model implemented here.

\section{ACKNOWLEDGMENTS}

The authors gratefully acknowledge the helpful comments received from Alessandro Bonanno, the anony- mous referees, and the section editor. The authors are also grateful to the University of Wisconsin Center for Dairy Profitability (http://cdp.wisc.edu/) for providing the data used to perform the present study.

\section{REFERENCES}

Aigner, D., K. Lovell, and P. Schmidt. 1977. Formulation and estimation of stochastic frontier production function models. J. Econom. 6:21-37.

Alvarez, A., C. Arias, and D. Roibás. 2005. Análisis de la calidad de la leche en un modelo microeconómico multi-output: El papel de la genética. Economía Agraria y Recursos Naturales 5:3-17.

Alvarez, A., J. del Corral, D. Solís, and J. A. Pérez. 2008. Does intensification improve the economic efficiency of dairy farms? J. Dairy Sci. 91:3693-3698.

Ball, E. 2009. Agricultural productivity in the United States. USDA ERS. http://www.ers.usda.gov/Data/AgProductivity/\#statetables. Accessed May 2009.

Bargo, F., L. D. Muller, J. E. Delahoy, and T. W. Cassidy. 2002. Performance of high producing dairy cows with three different feeding systems combining pasture or total mixed rations. J. Dairy Sci. 85:2948-2963.

Barham, B., J. Foltz, and U. Aldana. 2005. Expansion, modernization, and specialization in the Wisconsin dairy industry. Pages $42-48$ in Status of Wisconsin Agriculture: 2005. Univ. Wisconsin, Madison.

Bauman, D. E., R. W. Everett, W. H. Weiland, and R. J. Collier. 1999. Production responses to bovine somatotropin in northeast dairy herds. J. Dairy Sci. 82:2564-2573.

Bewley, J., R. W. Plamer, and D. B. Jackson-Smith. 2001a. An overview of experiences of Wisconsin dairy farmers who modernized their operations. J. Dairy Sci. 84:717-729.

Bewley, J., R. W. Plamer, and D. B. Jackson-Smith. 2001b. Modeling milking production and labor efficiency in modernized Wisconsin dairy herds. J. Dairy Sci. 84:705-716.

Bravo-Ureta, B., D. Solís, V. Moreira, J. Maripani, A. Thiam, and T. Rivas. 2007. Technical efficiency in farming: A meta-regression analysis. J. Prod. Anal. 27:57-72.

Bravo-Ureta, B. E., V. H. Moreira, A. A. Arzubi, E. D. Schilder, J. Alvarez, and C. Molina. 2008. Technological change and technical efficiency for dairy farms in three countries of South America. Chilean J. Agric. Res. 68:360-367.

Cabrera, V. E., R. Hagevoort, D. Solís, R. Kirksey, and J. A. Diemer. 2008. The New Mexico dairy industry: An economic engine. J. Dairy Sci. 91:2144-2150.

Carter, M. R. 1984. Resource allocation and use under collective rights and labour management in Peruvian coastal agriculture. Econ. J. 94:826-846.

Caudill, S. B., J. M. Ford, and D. M. Gropper. 1995. Frontier estimation and firm-specific inefficiency measures in the presence of heteroscedasticity. J. Bus. Econ. Stat. 13:105-111.

Cuesta, R. A. 2000. A production model with firm-specific temporal variation in technical inefficiency: With application to Spanish dairy farms. J. Prod. Anal. 13:139-158.

Dahl, G. E., R. L. Wallace, R. D. Shanks, and D. Lueking. 2004. Hot Topic: Effects of frequent milking in early lactation on milk yield and udder health. J. Dairy Sci. 87:882-885.

Dartt, B. A., J. W. Lloyd, B. R. Radke, J. R. Black, and J. B. Kaneene. 1999. A comparison of profitability and economic efficiencies between management-intensive grazing and conventionally managed dairies in Michigan. J. Dairy Sci. 82:2412-2420.

Erdman, R. A., and M. Varner. 1994. Fixed yield responses to increased milking frequency. J. Dairy Sci. 78:1199-1203.

Gribble, T. A. 2003. Discussion of optimum dairy size. International Dairy Housing Proceedings. January 29-31, 2003, Forth Worth, Texas. American Society of Agricultural and Biological Engineers, St. Joseph, MI.

Hallan, D., and F. Machado. 1996. Efficiency analysis with panel data: A study of Portuguese dairy farms. Eur. Rev. Agric. Econ. 23:79-93. 
Heshmati, A., and S. Kumbhakar. 1994. Farm heterogeneity and technical efficiency: Some results from Swedish dairy farms. J. Prod. Anal. 5:45-61.

Jaforullah, M., and J. Whiteman. 1999. Scale efficiency in the New Zealand dairy industry: A non-parametric approach. Aust. J. Agric. Resour. Econ. 43:523-541.

Jondrow, J., K. Lovell, I. Materov, and P. Schmidt. 1982. On the estimation of technical inefficiency in the stochastic frontier production model. J. Econom. 19:233-238.

Kolver, E. S., and L. D. Muller. 1998. Performance and nutrient intake of high producing Holstein cows consuming pasture or a total mixed ration. J. Dairy Sci. 81:1403-1411.

Kompas, T., and T. Chu. 2006. Technology choice and efficiency on Australian dairy farms. Aust. J. Agric. Resour. Econ. 50:65-83.

Kumbhakar, S., and K. Lovell. 2000. Stochastic Frontier Analysis. Cambridge Univ. Press, Cambridge, UK.

Lawson, L. G., J. Bruun, T. Coelli, J. F. Agger, and M. Lund. 2004. Relationships of efficiency to reproductive disorders in Danish milk production: A stochastic frontier analysis. J. Dairy Sci. $87: 212-224$.

Murova, O., and B. Chidmi. 2009. Impacts of Federal Government programs and specific farm variables on technical efficiency of dairy farms. Paper presented at the 2009 Southern Agricultural Economics Association Annual Meeting, Atlanta, Georgia (available at http://purl.umn.edu/46822).

Solís, D., B. Bravo-Ureta, and R. Quiroga. 2009. Technical efficiency among peasant farmers participating in natural resource management programs in Central America. J. Agric. Econ. 60:202-219.

Soriano, F. D., C. E. Polan, and C. N. Miller. 2001. Supplementing pasture to lactating Holsteins fed a total mixed ration diet. J. Dairy Sci. 84:2460-2468.

Stokes, J. R., P. R. Tozer, and J. Hyde. 2007. Identifying efficient dairy producers using data envelopment analysis. J. Dairy Sci. 90:2555-2562.

Tauer, L. W. 1993. Short-run and long-run efficiencies of New York dairy farms. Agric. Resour. Econ. Rev. 22:1-9.

Tauer, L. W. 1998. Productivity of New York dairy farms measured by nonparametric Malquist indices. J. Agric. Econ. 49:234-249.

Tauer, L. W. 2001. Efficiency and competitiveness of the small New York dairy farm. J. Dairy Sci. 84:2573-2576.

Tauer, L. W., and K. Belbase. 1987. Technical efficiency of New York dairy farms. Northeastern J. Agric. Resour. Econ. 16:10-16.

Tauer, L. W., and A. K. Mishra. 2006. Dairy farm cost efficiency. J. Dairy Sci. 89:4937-4943.

USDA. 2007. Milk production, disposition and income, 2006 summary. Natl. Agric. Statistics Serv., Washington, DC.

Wagner, A., R. W. Palmer, and J. Bewley. 2001. Producer satisfaction, efficiency and investment cost factors of different milk systems. J. Dairy Sci. 84:1890-1898.

Wronski, M., M. Cichocki, K. Borkowska, and J. Redmer. 2007. Milk production efficiency as dependent on scale of production and cow management systems on dairy farms. Polish J. Nat. Sci. 22:5060 . 